\title{
ESP AS A CHALLENGE TO CONFRONT - A CASE STUDY OF TECHNICAL ENGLISH IN A PRE-INTERMEDIATE LEVEL UNIVERSITY CLASSROOM
}

Lenka Lustigová

\begin{abstract}
Drowned in explosive amounts of information, new technology developments, globalisation, international job opportunities and large-scale job migration, English for Specific Purposes (ESP) courses are faced with the increasing requirement of tailoring languagelearning to accommodate employer or employee specialisations. This dynamism is currently being transmitted to courses at the university level, along with the accompanying challenges for all involved. This paper reviews these potential barriers to implementation of ESP courses for students with low proficiency of English, taking a pre-intermediate-level Technical English (TE) course at the Czech University of Life Sciences Prague as a case study. After analysing various scholarly references aimed at ESP, the classroom-based research for this paper confirms the feasibility and efficacy of implementing ESP and TE, in particular, even into pre-intermediate classrooms. The self-motivating design of 6 TASKS, as well as authentic video sessions, combined with a student survey and teacher observations, all serve to point to ESP introduction on the pre-intermediate level as achievable in terms of application and resourceful regarding future life-career situations in which students will eventually find themselves.
\end{abstract}

\section{Key Words}

Authentic problem-solving tasks, ESP, pre-intermediate, task-based learning, Technical English, video usage
Czech University of Life Sciences Prague lustigova@pef.czu.cz

\section{ARTICLE INFO}

Article type

Full research paper

doi: 10.7160/eriesj.2013.060408

Article history

Received: September 29, 2013

Received in revised form: December 16, 2013

Accepted: December 20, 2013

Available on-line: December 31, 2013 


\section{Introduction}

As English has increasingly become the accepted "lingua franca" internationally, many learners of the language seek course-based opportunities to suit their specific professional needs. As such, there is a growing demand for English for Specific Purposes (ESP) courses not only within professional environments, but also in various academic and vocational contexts. This paper focuses on teaching ESP at the university level, with special consideration given to the challenges and limitations of teaching ESP to students with pre-intermediate level and/or inadequate knowledge of general English fundamentals and often, without any prior professional experience.

'English for specific purposes' has been defined by a multitude of writers and researchers. The frequently cited definition of Hutchinson and Waters (1987: 21) stipulates that ESP represents a type of language teaching in which all decisions as to content and method are based on the learner's motivation for education, "ESP is an approach to language teaching which aims to meet the needs of particular learner." Considering this general, theoretical definition of ESP, it is obvious that it contrasts with General English at ground level, given the course content and aims. Although General English courses may be similarly customised to meet students' needs, either as a group or on an individual level, this does not serve as the original course objective. Hutchinson and Waters (1987: 53) have explained in detail:

...what distinguishes ESP from general English is not the existence of a need as such but rather the awareness of the need. If learners, sponsors and teachers know why the learners need English, that awareness will have an influence on what will be acceptable as reasonable content in the language course and, on the positive side, what potential can be exploited. Thus, although it might appear on the surface that the ESP course is characterised by its content (Science, Medicine, Commerce, Tourism etc.), this is, in fact, only a secondary consequence of the primary matter of being able to readily specify why the learners need English. Put it briefly, it is not so much the nature of the need which distinguishes the ESP from the General course but rather the awareness of a need. This being said, we would still maintain that any course should be based on an analysis of learner need.

Keeping in mind this precise focus on students' needs, Orr corroborated ten years after Hutchinson and Waters, emphasizing that ESP courses therefore differ from General English courses by their narrow focus upon specific linguistic knowledge and the communication skills necessary to accomplish specific purposes within an explicit discipline or profession (Orr, 1997: 11). With the continued expansion of ESP courses over the ensuing decades and the accompanying, pertinent research, Thornbury (2006: 75) further explains that the contents of an ESP course do not consist of topic-specific vocabulary only. The course can have a much broader functional depth by concentrating concurrently on skills expansion and the development of key competencies, such as the reading and writing of the texts associated with the given field or profession. Similarly, increased importance may be given to the growth of communication skills and inter-cultural competencies in particular. Finally, according to Ruiz-Garrido, PalmerSilveira and Fortanet-Gómez (2010: 8), "ESP provides skills and tools to professionals and specialists to communicate and transfer information and knowledge. It establishes the special 
discourse used in specific settings by people sharing common purposes. There are as many specialised languages as there are professions."

Furthermore, whilst the preferred learning style of the educational establishment should be considered and integrated into the course development, the ESP course likewise needs to be matched with the information gathered on learners' capacities, attitudes and expectations, as underlined by Thornbury (2006: 142). When performing this initial needs-analysis, ESP's fundamental characteristics must be taken into consideration:

Strevens (1988: 1-2) states that ESP consists of English language teaching which is:

- designed to meet the specified needs of the learner;

- related in content (i.e. in its themes and topics) to particular disciplines, occupations and activities;

- centred on the language appropriate to those activities in terms of syntax, lexis, discourse, semantics, etc., and the resultant analysis of this discourse;

- may be restricted to and/or highly focused on the language skills to be learned (e.g. such as reading only);

- may not be taught according to any pre-ordained methodology [the concept of simultaneous development with the market, i.e. on-par course development]

Dudley-Evans (1998: 4-5) has revised Strevens' definition underlying that ESP:

- is defined to meet the specific needs of the learner;

- makes use of the underlying methodology and activities of the discipline it serves;

- is centred on the language (grammar, lexis, and register), skills, discourse and genus appropriate to these activities;
- may be related to or designed for specific disciplines;

- may use, in specific teaching situations, a different methodology from that of general English;

- is likely to be designed for adult learners, either at a tertiary level institution or in a professional work situation. However, its applications are being explored in terms of adaption to learners at the secondary school level;

- is generally designed for intermediate or advanced students;

- most ESP courses assume some basic knowledge of the language system, yet it can also be used successfully with beginners.

Within the academic context, this approach puts the students' needs first, as they are properly analysed towards efficient learning of the skills necessary to function within both their field of current study and potential future jobs. The overall analysis of the learners' language needs should be performed in advance of designing a course and may be done in a variety of ways, including: questionnaires conducted with the probable course students at the time of registration, interviews with potential job employers in human resources departments about what they are seeking in candidates, on-site observations of professional situations and internet-research, which offers an increasingly accurate reflection of the developing job market.

With exciting velocity, ESP teaching has indeed become a fundamental part of most university language teaching programmes and an inseparable part of TESOL (Teaching English as a Second Language). Drowned in explosive amounts of information, new technology developments, globalisation, international job opportunities and large-scale job migration, ESP courses are faced with the increasing requirement of 
tailoring language-learning to accommodate employer and employee specialisations. The dynamism of the world has thus challenged the TESOL world anew, bringing unprecedented perspectives and opportunities into the classroom. Although some specific research into this sector has been carried out, little attention has been given to the integration of ESP into preintermediate-level students curricula. Therefore, the research which this paper and case study presents is seminal. It aims at bringing to the forefront the need for integrating ESP into language teaching programmes and at verifying the feasibility and efficiency of such programmes even for pre-intermediatelevel university students who have a very limited knowledge of general English.

Given the nature of this study, the objectives of this paper are to verify the viability of teaching ESP to A2 (pre-intermediate) level learners and larger integration of ESP into a growing number of university-level classrooms, based on practical implementation of specific teaching tools. This paper discusses challenges and limitations of teaching ESP to pre-intermediate-level students, offering procedures to make ESP teaching at A2 levels feasible and efficient. It focuses on selected teaching methods which can be implemented in the teaching-learning process to support the fulfilment of both the students' needs and societies' requirements. These teaching methods are then analysed and their results assessed based on the teacher's observations and the students' feedback, generated in the form of survey. Lastly, the A2 learners' attitudes, satisfaction and needs are examined to offer a practical solution to the multi-faceted issues faced by other university teachers who decide to teach ESP to preintermediate-level students. Various sources, tools and methods are then suggested as appropriate for pre-intermediate-level university students and to encourage universities to implement ESP into their language teaching programmes.

The methodology used to formulate this paper comprises a scholarly assessment of teaching ESP to pre-intermediate-level students, suggesting multiple methods to make the teaching of ESP at pre-intermediate-levels more achievable within the university context. This is followed by a description of their implementation in practise. The concluding assessment is accompanied by an examination of the students' attitude, satisfaction, and need-factors based on survey results. This observation research gives way to this paper suggesting a workable, cohesive integration of ESP teaching methods into pre-intermediate-level language classes. All of the described procedures are classroom-tested, as evidenced by the number of students, genders, ages, professional goals and students' survey results, thus offering direct solutions and opportunities for the ESP field at large. Subsequently, this paper provides an extensive methodological discussion of the challenges and limitations of ESP implementation into language teaching programmes to pre-intermediate-levels, including those faced by both the teacher, as well as the student, before offering various strategic responses to specific classroom situations. Special consideration is given to the students' attitudes, needs, and motivational issues. Finally, the scholarly results are summarised with a reflection on the importance of sensitive ESP integration into university language teaching programmes, considering the barriers which are stipulated, explored and discussed. 


\section{Material and Methods}

For the purpose of this study, 'pre-intermediate-level' students were defined based on the Common European Framework of Reference (CEFR) as A2 students. The Council of Europe (via the CEFR) defines A2 level students as basic users of English who can understand sentences and frequently-used expressions related to areas of most immediate relevance (e.g. very basic personal and family information, shopping, local geography, employment). They can communicate in simple and routine tasks requiring a simple and direct exchange of information on familiar and routine matters. They can describe aspects of his/her background, immediate environment and matters in areas of immediate need. (Retrieved on September 1, 2013 at http://www.coe.int/t/dg4/education/elp/elp-reg/Source/ Global_scale/globalscale.pdf )

The educational establishment, the Czech University of Life Science Prague (CULS), was the research site for this paper. However, although almost twenty-four years have passed since the enormous revolutionary and political changes within the former Eastern European countries, the general level of knowledge of English is not satisfying on the whole. This has led to the need for ESP courses not necessarily being easily realised. For example, at the university under examination, the prevailing number of students surprisingly still enrols into lower-level courses.

Technical English is distinguished from General English by its more specialised vocabulary and its more narrowly defined field of vocabulary (e.g. production, planning, maintenance, purchasing, testing, laboratory work, project work, and quality issues). Teaching TE also involves coaching learners in such skills as speaking and listening, essential to on-the-job tasks.
Other important skills comprise reading and understanding technical documentation, as well as writing technicallycomplicated emails, as highlighted by Hollet (2005:4).

The following research is based on observing, monitoring and questioning the classes of the A2 Technical English course, who had little or no experience within the professional world. (Their prior experience to taking this course may have consisted of a single-term internship, etc.) The term 'Technical English' (TE) is used to cover English taught as a second language to a range of full-time students who intend to work in the technical sector. These students are future technicians, engineers, and scientists working in a wide variety of technical fields.

\section{Course Specifics}

The research methods and subsequent results below were executed and analysed over the course of four full-length university semesters at the University of Life Sciences Prague in the classes of 80 pre-intermediate-level (A2 = pre-intermediate) Technical English students. Before its introduction, the syllabus was elaborated and the course designed, eventually implementing essential improvements, based on the monitoring during the first two semesters. Likewise the students' feedback and attitudes survey were assessed at the course-end by the students (76 out of 80 which actually returned the questionnaire complete). The survey was conducted in the form of a questionnaire consisting of 10 questions. Where appropriate, the answers were given in a scale from 0 to 10 , considering the learners' pre-intermediate level of proficiency. Class sizes varied from 15 to 23 students, included both genders (however the majority were male - $90 \%$ ) and covered an age range of $19-21$ year olds, mostly first-year students. The courses were aimed at full-time students. All the students had taken English 
as a second language for a minimum of four years before taking this course at the university. However, their level of English proficiency was generally very low with most at the A1-A2 levels (elementary and pre-intermediate). The majority of the students were native speakers of Czech; however some of them came from multinational backgrounds (including Ukrainian and Vietnamese families). The Technical English course was a course specifically designed for B.A. degree majors in Agricultural Machinery (specialising in machinery operation control and design or service and renewal of machinery and processing equipment), Road Transportation and City Traffic, Waste Disposal Technology and Techniques, Technological Equipment of Constructions, Trade and Business Dealing with Machinery, Information and Control Technology in the AgroFood complex. Thus, it was clear that the students' career focus would strongly benefit from this especially-developed TE course, even though the students were non-language majors. The course comprised 24 contact lessons (once per week, 90 minutes) per semester held over 12 weeks. The course was not compulsory, in that the students were not required to take the TE class for their degree major; instead, they had the option of choosing a General English course. However, given the overall positive evaluation the ESP course received, it was increasingly being recommended by the students' on-site academic advisors and by word of mouth.

Given that the course was attended by students from a variety of scientific backgrounds, it was necessary to set a common goal that would benefit all the students. Thus, general technical terminology and skills were focused on, making the technical context and vocabulary also appropriate for students who had already taken the elementary General English course. As the course's fundamental material, the textbook Tech Talk (Pre-
Intermediate) was selected. The lessons were supplemented by multiple videos, printed materials, internet games and exercises which established a more authentic context from the technical point of view, fostered a positive learning atmosphere, drew on the students' creativity and overall helped to make the meanings of vocabulary and situational settings clear. As the students would most probably emerge into multi-cultural work environments, they were exposed to listening exercises recorded by a variety of native and non-native speakers.

As stated earlier, it was not only the needs of the technical learners, but also their lack of English proficiency which influenced the course design, content, and selection of methods and tools. For example, much attention was given during the course to the language of instructions to "prepare learners for understanding and explaining work tasks, and also for the reading of instructional materials such as manuals and equipment documentation", as emphasized by Hollet (2005: 5). Substantial consideration was also given to the language of numbers and measurements. The order of introduction of linguistic forms and grammar structures was likewise modified, when compared to the generally-used sequence in General English. Some grammar and functional forms were omitted, whilst others were established earlier on, even though they are usually left aside until a later stage in a general course. Specifically, in contrast to General English A2 courses, A2 TE students were introduced and trained in a range of different passive forms (It's made of..., It needs fixing, It was manufactured by..., etc.) and comparative forms of adverbs (for example more cheaply, more efficiently, etc.), as referred to in Hollet (2005: 5). Yet the course also had to cover more than only a technical context, since the students needed some basic 'survival' language for greetings, travelling, buying items, asking for help, etc. However, 
even this survival-level language was tailored to the ESP goal, as the accompanying vocabulary was provided within the scope of different technical contexts. Due to the variety of academic fields represented by the individual students, a general level of technical terminology was established as a grounding point and the course then subsequently concentrated on additional technical words with higher frequency as inspired by Hollet (2006: 6).

As a form of interim assessment, the task results and the students' performance were generally commented on by both the teacher and the students themselves. Major lexical and grammatical insufficiencies were discussed and corrected. Most of the comments were highly appreciated on the part of the teacher and students. Based on the feedback, the learners endeavoured to utilise the lessons and learning opportunities to a much greater extent. The on-going teacher's encouragement to speak aided in overcoming any obvious barriers of the non-proficient learners and thereby contributed invaluably to practising communication skills. This continued speaking practise also had the advantage of highlighting the correct usage of technical vocabulary in simple grammatical structures for eventual use in the students' future technical careers. On the whole, it was observed in this ESP course that if the overall teaching-learning process was to be worthwhile, the following principles needed to be maintained, as underlined by Lustigova (2012: 51):

- the course and lesson aim defined and strictly adhered to;

- the feedback immediate;

- the evaluation selective, yet sympathetic in a friendly, constructive manner.
In this manner, the learners had the opportunity of learning about the mistakes or any insufficiencies directly. On the part of the teacher, sufficient time was continually devoted to feedback throughout the course; otherwise any major knowledge improvement would never have been fully accessed.

\section{Method-in-Practise: Authentic problem-solving tasks for the course}

Within the course, all the authentic problem-solving tasks were grounded on task-based learning, described by Harmer (2007: 71) as "the performance of meaningful tasks central to the learning process." It is believed that "if students are focused on the completion of a task, they are just as likely to learn language [as they would be] if focusing on language forms." Several authentic problem-solving tasks, based especially on the learners' subject-related experiences, were designed to extensively practise all of the language skills within realistic technical contexts. Substantial time was devoted by the teacher to instructing the students, prior to accomplishing the given assignment.

TASK 1 required the students to prepare comprehensive presentations, comparing two companies from the same industry with a focus on the companies' logistics. The actual web pages of the selected companies were presented. Essential vocabulary was highlighted and either explained or translated into native language (L1). Active participation by both the presenting student and the responsive colleague students made for a dynamic lesson and considerable enthusiasm. Within the presentation, other technical topics were also discussed, as pertinent to the given companies, and related vocabulary was 
practised. The bullets below offer a concise summary of the vocabulary and grammatical points which were targeted and practised extensively via TASK 1:

- vocabulary of time (within this fiscal year, at the end of the first quarter);

- vocabulary of parts and attachments (rim, slot, platform, base, attached to, supported by);

- vocabulary of materials (steel, rubber, leather, etc.);

- money-related terminology (net worth, fiscal earnings);

- quality issues (quality versus quantity, quality control);

- comparative adjectives and adverbs (higher, faster, more efficiently);

- first conditional (If they buy a new plant, it'll help);

- processing verbs (draining, sorting, shredding, etc.);

- sequence statements (First..., after that..., then..., etc.)

The required class delivery of the findings ( 3 - 5 minutes in length) required both reading and researching of on-line documents. The focus of this exercise was given to reading and, afterwards, to using of proper language and practising grammar and vocabulary. Presentation skills were not assessed and evaluated, as the pre-intermediate level of English proficiency did not enable the students to focus on proper presentation skills and other soft skills. However, after the initial feelings of embarrassment or self-consciousness were overcome, it was obvious that the presentation skills of the students were indeed improving and this, in and of itself, served as a first step to helping students face similar situations in their future studies and careers. As confirmed by Harmer (2007: 282), such "webquest is a good example of a multi-skill project. There is reading and writing, and speaking and listening (in the discussions sessions with the teacher and other students which can occur at various stages of the process)."

In order to encourage linguistic growth from all the students present, the student colleagues-audience was required to ask 'open' questions (Wh- questions; e.g. Where does it go? How long does it take? When is the plant going to be set up?, etc.). As the presentations progressed throughout the semester, the cumulative improvement on both the part of the student presenters and the student audience was evident. Not only did the actual presentations become increasingly well planned and given, but the student audience grew in self-assurance as to their own capacity to ask related questions. This was demonstrated by less prompts required from the teacher and a longer time needed to be allotted for the question-answers sessions.

For TASK 2, students were asked to bring technical objects of their own choice (e.g. small, hand-held farm equipment, portable machining tools, etc.) and deliver as detailed a description as possible in front of the class and/or within groups of four. Length of presentations varied, depending on the complicated nature of the technical item, but averaged out to approximately 4 minutes. The students practised both old and new vocabulary of shapes (cylindrical, triangular, cube), sizes $(40 \mathrm{~cm} \times 21 \mathrm{~cm} \times 60$ $\mathrm{cm}$, non-standard size), dimensions (2 acre $x 6$ acre field, 200-metre building, two-tonne truck), increasingly defined colours (cobalt, magenta), materials (steel, tin, brass, copper), material properties (ductile, durable, non-permeable) and other adjectives describing the materials. They were required to use passive structures (as explained in TASK 1) and explain causes and effects (When X happens, Y shortly follows, You cannot do X, without doing $Y$.). This prompted a short follow-up exercise, designed to be studentgenerated, within the classroom. Students described the object 
without telling or showing what was in fact being described; the rest of the class or group had to guess what the object was without seeing the real object. By touching and holding the individual parts and physically having the object present in the classroom, the students' interest was maintained and even raised significantly. Such settings established a genuine environment and the students were exceedingly motivated to deliver as accurate of descriptions as possible. On several occasions throughout the semester, the teacher was asked to repeat TASK 2 . This was considered a stimulating success rate. Aiming to provide as true a technical context as possible, students were asked in TASK 3 to design and make a drawing of their own simple device for putting out a candle, squeezing a toothpaste onto a toothbrush, turning off an alarm clock, crushing and recycling an empty drink can or any another device design of their choice. The schemes were presented to the entire class through interactive whiteboard (IWB). The language of cause and effect (If you pull..., it goes up. X makes $Y$ happen) was practised. Students were required to use strong verbs of control (rotate, turn, increase), machine-part vocabulary (pulley, pivot, spring,) phrases of rising and falling (go up, go down, rise, fall, elevate, descend). All the schemes were also submitted in a printout version, with a detailed written description of individual parts and of how the device's mechanism functioned (minimum of five sentences). The teacher's feedback on both the speaking and writing part of the project was much appreciated. Even very simple schemes provided students with enough opportunities to consolidate their language skills and practise speaking, writing and listening in a great extent. As an authentic problem-solving task, with designs largely invented by the students themselves, the presentations, schemes, and pictures brought a lot of humour and fun into the class and helped establish a friendly, non-judgmental atmosphere. The audience was invited to ask questions. Although students overall valued the task, they could demonstrate substantial debate skills in terms of fine-tuning the device designs. This would be something to inculcate over a period of two semesters, with a repetition of TASK 3 at the start and end of the semesters, in order to facilitate opportunities for debate for the students and teaching opportunities for the instructor on how to ask and answer effective follow-up questions. However, and more importantly, $100 \%$ of the students were engaged in the project with enthusiasm and creativity.

Developed to practise test procedure vocabulary, TASK 4 required students to bring in their own small toy-sized or remote-controlled cars and motorcycle or skiing helmets to be tested. If a certain student did not own such an item, they were requested to borrow one from a relative, friend, neighbour, etc. Once in the classroom, several sample safety-test recordings were presented to them ahead of time as reference tools. After the recordings, specific technical vocabulary and grammar structures that were pertinent to safety tests were discussed and studied on the board. This was followed by a hand-out, distributed on site, to reinforce the usage of specific terminology. The students were then asked to present their own safety tests of the items they had brought. After approximately 15 minutes of preparation in small groups, students began playing the roles of dummies used for car or helmet safety tests in realenvironment demonstrations. TASK 4, in particular, proved to be a motivating exercise for terminology of roles and processes (to take or play the role of, in this sequence, in the final stage of the test... ), vocabulary of warnings and safety instructions (Beware!, Do not touch - danger of death!, If instructions are not followed, injury may result.), as well as the present passive (It's designed 
by the Health and Safety Institute.). It was obvious that this type of exercise, when the students were allowed to stand up and move freely about the classroom to perform and demonstrate the tests accounted for a varied, inspiring teaching-learning environment, whilst focusing on consolidation of technical vocabulary. The group members were either assigned by the teacher or the students determined the groups by themselves. This task required a significant amount of teacher monitoring, as the initial concept of role-playing was not inherent to all the students. With some small encouragement, however, the task was enjoyed by most of the students.

Over the semester, it became apparent that technical students enjoy describing parts of machines and technical processes, thus, TASK 5 was developed. A vacuum pump, and other similar small machines and machinery parts (engine, transmission, headlights, etc.), were brought into the classroom. They were dismantled within groups by the students themselves and the most important parts were named and set aside. Given the benefit of being able to physically touch the individual parts and correctly repeat the accompanying words, the students learned additional technical terminology very easily (hose, shaft, hub screws). Moreover, they practised the language of attachments and locations (leads to, attached to, linked, behind, on the front of), which included phrasal verbs. $100 \%$ of the students were engaged in the project. This direct, hands-on manipulation of the actual objects permitted the students to acquire the essential language skills in a much more efficient manner. Generally, the students offered insightful and appropriate comments. In the small groups which were organized, even the quiet students wanted to contribute to the dialogue process. On the whole, the group work allowed for those students, who were less comfortable with the communication process, to acclimatize to the task at a more personal pace. Long-term, this aided the total classroom atmosphere.

To further provide genuine technical contexts during the lesson, students were grouped and invited to browse for technical drawings and documentation as a part of TASK 6 . The drawings and documentation were part of technical and businessoriented magazines, books and manuals which the teacher had brought into the classroom. Students were then asked to write down open questions for other groups based on the drawings, within the language capabilities they possessed. This was followed by a question and answer session. The overall process was monitored by the remainder of the class, which delivered fruitful feedback on grammar and pronunciation mistakes, in particular. Although this exercise was quite strenuous for the majority of the students, they indeed prised the praise for their efforts and subsequent feedback on the task. By repeating the exercise using different visuals at the following lessons, the students had the opportunity to improve their performance significantly, in terms of language used and questions asked. Helping to overcome any previous known language obstacles, TASK 6 was designed by the teacher to help drill basic questions about dimensions and sizes, as well as fixed knowledge of numbers and pronunciation of unit measurements. It was noted that the students acted responsibly during the group work. For the most efficient teaching-learning process to occur, small groups of 2-3 proved ideal, after an initial set-up of 3-5 per group. The groups were systematically rearranged as advised by Harmer (2007: 167). In addition, the groups were re-organized the second time that the exercise was used, thus offering a different set of students the occasion to cooperate. 


\section{Method-in-Practise: Real video session tasks}

According to Lonergan (1984: 4-5), “the outstanding feature of video films is their ability to present complete communicative situations. At their best, video presentations will be intrinsically interesting to language learners. The learner will want to watch, even if comprehension is limited." Throughout the academic year, several authentic technical video recordings were selected and presented to the students, who, in turn, showed great interest in implementing them into the lesson plan. The following are several examples of the recordings used during the lessons:

- video 'Wacky Warnings' (http://www.youtube.com/ watch? $\mathrm{v}=\mathrm{IXHeC} 8 \mathrm{dvfaM})$

This video distinguished itself in terms of imperative clauses (Don't use..., Keep this...), warning expressions (Danger!, Warning!, Attention!) and suggestion forms (Why don't we...!, How about...!, I think we should...!). The overview of funny warning labels, recorded around the world, yet likewise often seen by students in their daily lives, brought immediacy to the classroom. It also brought good humour, setting a friendly atmosphere in the classroom. This led to the follow-up exercise of the learners designing their own wacky labels and warnings or inventing a new gadget and the eventual presentation of this to the class.

- Video of how to replace an oil filter (http://www.ehow.com/ video_7876560_replace-oil-filter.html\#ixzz2KFTMfHGQ)

This recording of the actual activity of replacing an oil filter in an ordinary car, which is regularly carried out by most of the students, received enormous interest. The language for instruction-giving and for carrying-out procedures was practised, alongside verbs for describing physical tasks (locate, unscrew, repeat), whilst adverbs of manner (gently, tightly, carefully) were simultaneously introduced. As follow-up, students were asked to describe the process of replacing the filter. This lead to a spontaneous discussion of replacing other car parts.

- Hoover dam video (http://www.youtube.com/ watch?v=D7_rzojvKdE).

This video served as a backdrop for practising numbers, dimensions and measurement units, which were derived from the actual language in the video. Another goal, using this video, was to generate questions concerning any other monumental engineering construction worldwide and give answers in pairs or groups.

- James Bond's gadgets video (http://www.youtube.com/ watch? $\mathrm{v}=\mathrm{knSw}$ _q6CTns)

This video was especially well-received by the learners, since the students were familiar with most of the James Bond movies and the devices used therein. Besides practising basic technical vocabulary, this video gave shape to the language of possibilities (It can..., It enables...) and helped provide a basis for reviewing object description vocabulary (focusing on shapes, materials and material qualities).

All of the above stated examples of recordings were used sensitively, so as not to overwhelm the students; otherwise, the original language of these videos would make an overly difficult listening and comprehension exercise for A2 students. Without proper pre-sessions of video preparation, the lessons would not have met the objectives desired by the teacher and would have consequently diminished the students' motivation. In order to prepare, all the students received hand-outs of the audio scripts in advance. These scripts were read collectively, 
which led towards better command of the content and helped in the acquisition and understanding of essential vocabulary and grammar structures. Afterwards, time was allotted for questions concerning unknown vocabulary, which was then explained either in English or translated into L1, depending on the level of the learners' understanding and the complexity of the topic at hand. Following the initial viewing of each video, the students were given another audio script hand-out with some of the technical items left blank. Their task was to listen for and fill in the designated technical words, numbers, measurements, etc. which were omitted in the hand-outs. The follow-up discussions and speaking exercises made for effective exercises, as the level of difficulty was not over-challenging, yet still stimulated growth. To summarise, the four groupings of language skills were able to be practised successfully (including reading, writing, listening, and speaking) using the described video sessions.

\section{Results}

This paper has demonstrated the fruitful application of methods and strategies for teaching ESP within a TE context, specifically to pre-intermediate students at the university level. The abovedescribed and documented scholarly work confirms that ESP/ TE is feasible for A2 level students and may be progressively implemented into more university-level language classrooms. It was observed that the authentic problem-solving tasks and real video session tasks, targeted as a tool to overcome the challenges and limitations of teaching TE to pre-intermediate classes of English learners, proved to be highly effectual. The feasibility and efficiency of the overall process of implementing ESP into pre-intermediate-level language classrooms was thereby confirmed, based on the results of teacher's observations and the survey of the students' attitudes, satisfaction ratings and current or future needs.

This paper has likewise revealed that the productivity of the process on the whole depends on multiple variables, comprising not only the teacher's preparation, presentation, follow-up and assessment, but also the students' motivation. In this case, implementing ESP into the pre-intermediate-level English courses was simplified, as the course was usually attended by Technical Faculty students who were quite receptive to the course's technical content. By using the authentic problemsolving tasks and real video session tasks, it was possible to offer A2 TE-content material that both addressed the life situations outside the classroom and challenged the students to make the most of the classroom experience, spurring ongoing student interest. The benefits of task-based learning were especially obvious in discussions over the drawings and object descriptions, which proved the findings of Kavaliauskiene (2005: 70). As the course progressed over the semester, the teacher observed that the entire class benefited from a friendlier, more interactive atmosphere. In terms of teacher-to-student ratios, the authentic problem-solving tasks and real video session projects could be used more successfully when the class size was smaller; ideally, the number of students ranged at 15-17. Smaller classes were also more resourceful from a management point of view, especially given the limited classroom time, the continued need for teacher monitoring and guidance, the students' own attention span and participation, and the vital student-teacher feedback.

By and large, the course's effectiveness was correspondingly established by the fact that the students manifestly improved their speaking, writing, reading and listening skills. This 
was evidenced by interim and year-end testing, the students' preparation for the lessons, the regular submission of required homework (presentations, schemes, etc.) and increased responsibility in terms of classroom activities. Course attendance was maintained at a stable level of $85 \%$. Looking at the larger, out-of-classroom context, the students also benefited from the lessons by gaining initial presentation skills and other soft skills which could be developed further on for their future career benefit.

In order to validate the above-recorded teacher's observations on the feasibility and efficiency of teaching ESP to preintermediate-level students within a TE context, a student survey was taken at the end of each academic year. The survey was meant as an indicator of the students' attitudes and satisfaction with the course, summarising their needs. Students were given ample time to respond to the questions. The survey content and selected answers are shown in Table 1 . The students expressed their opinions and suggestions mostly in the form of written answers; the most typical and prevailing responses are provided below in their shortened version.
Table 1: Survey of student's attitudes, satisfaction and needs

\begin{tabular}{|c|c|c|}
\hline & Questions & Students' answers \\
\hline 1. & $\begin{array}{l}\text { Why did you enrol into } \\
\text { this A2 TE course? }\end{array}$ & $\begin{array}{l}\text { '... it was recommended by some students from } \\
\text { the last year.' } \\
\text { '... to learn technical words and phrases.' } \\
\text { 'I'm interested in technical stuff.' } \\
\text { 'I need only A2 level and at the same time I } \\
\text { wanted to learn more specialized language.' ' } \\
\text { 'Any specialized and content focused English is } \\
\text { more beneficial than General English.' } \\
\text { 'The course seemed more interesting than a } \\
\text { regular General English course.' }\end{array}$ \\
\hline 2. & $\begin{array}{l}\text { Will you need ESP } \\
\text { focused language in } \\
\text { your future professional } \\
\text { career? }\end{array}$ & $\begin{array}{l}\text { 'Yes, for sure.' } \\
\text { 'Definitely. Even now I read technical } \\
\text { documentation in English in my part-time job.' } \\
\text { 'Probably.' } \\
\text { 'I think, A2 represents the very basics required } \\
\text { by most of the employers.' }\end{array}$ \\
\hline 3. & $\begin{array}{l}\text { How useful is the } \\
\text { introduction of an } \\
\text { A2 TE course into the } \\
\text { university curriculum? } \\
\text { (0-10, where } 0 \text { marks } \\
\text { the lowest level and } 10 \\
\text { the highest) }\end{array}$ & The average score is 9. \\
\hline 4. & $\begin{array}{l}\text { Did the course meet } \\
\text { your expectations? If the } \\
\text { answer is lower than } 5, \\
\text { please explain why. (0 } \\
-10 \text {, where } 0 \text { marks the } \\
\text { lowest level and } 10 \text { the } \\
\text { highest) }\end{array}$ & The average score is 9. \\
\hline
\end{tabular}




\begin{tabular}{|c|c|c|}
\hline & Questions & Students' answers \\
\hline 5. & $\begin{array}{l}\text { Do you consider the } \\
\text { length of the two- } \\
\text { semester A2 TE course } \\
\text { sufficient or would } \\
\text { you appreciate a } \\
\text { continuation course? }\end{array}$ & $\begin{array}{l}\text { 'I would welcome follow-up course.' } \\
\text { 'I would make the subject compulsory for all } \\
\text { Technical Faculty students.' } \\
\text { '...the course was sufficient. It gave me the basics } \\
\text { and the rest I will learn in a job if necessary.' } \\
\text { 'The B1 TE course should be offered at the } \\
\text { university as well.' }\end{array}$ \\
\hline 6. & $\begin{array}{l}\text { What is your } \\
\text { evaluation of the } \\
\text { course, considering the } \\
\text { knowledge gained? }(0- \\
\text { 10) }\end{array}$ & $\begin{array}{l}\text { The average score is } 8 . \\
\text { Some students' explanations were added, } \\
\text { for example: 'the lower score is due to my } \\
\text { laziness and not positive attitude to self-study.' }\end{array}$ \\
\hline 7. & $\begin{array}{l}\text { What parts of the } \\
\text { lessons did you consider } \\
\text { the most efficient or } \\
\text { beneficial? }\end{array}$ & $\begin{array}{l}\text { 'Device and machines descriptions while having } \\
\text { the object present in the classroom.' } \\
\text { '... technical vocabulary.' } \\
\text { '... speaking parts, dialogues, role playing.' } \\
\text { '...listening and watching real dialogues and } \\
\text { videos.' }\end{array}$ \\
\hline 8. & $\begin{array}{l}\text { What parts of the } \\
\text { lessons do you consider } \\
\text { inefficient or not as } \\
\text { beneficial? }\end{array}$ & $\begin{array}{l}\text { Very few responses. The students that did } \\
\text { respond wrote that they did not see the } \\
\text { value of group and pair work. }\end{array}$ \\
\hline 9. & $\begin{array}{l}\text { What did you miss in } \\
\text { the lessons or course as } \\
\text { a whole? }\end{array}$ & $\begin{array}{l}\text { Very few responses. A few students } \\
\text { suggested that 'Even more presentations } \\
\text { would be a bonus. I believe that there are never } \\
\text { enough speaking opportunities at any English } \\
\text { lesson.' }\end{array}$ \\
\hline 10. & $\begin{array}{l}\text { What activities would } \\
\text { you like to focus on in a } \\
\text { future course? }\end{array}$ & $\begin{array}{l}\text { 'I would need more listening exercises to really } \\
\text { comprehend spoken Technical English.' } \\
\text { '... more grammar practice might improve the } \\
\text { fluency of my speaking.' }\end{array}$ \\
\hline
\end{tabular}

Based on the students' responses, it is obvious that the initial motivation of the students was quite high, since they expected and aimed to study new content which focused more on their potential future technical careers. The course was assessed as highly beneficial, meeting the students' expectations to a great extent. Likewise, they appreciated the significantly high level of gained knowledge, thus, considering the course a boon. Most of them would appreciate a follow-up continuation course which is, unfortunately, not offered at the Czech University of Life Sciences Prague at present. The implementation of the authentic problem-solving tasks and real video sessions among other activities was highly valued. As evidenced in the survey above, students especially grasped onto the authentic technical contexts through the physical presence of technical objects, documents, schemes and presentations. Of particular note is that the learners were aware of the fact, that even though the focus of the technical content was the priority, they also needed to work on grammar and function structures to maintain and develop a certain 'survival' language level, as well as make their communication and speaking more fluent.

\section{Discussion}

Teaching ESP at university level is no longer a choice. It has become a necessity and thus challenges and limitations must be addressed accordingly. Formerly, ESP was designed especially for intermediate and advanced students. However, the level of General English proficiency of many non-language students is, by and large, not at a substantial level. In spite of this fact, and specifically in the Czech university system, it is progressively being considered useful for them to take ESP courses, rather than General English courses, in order to steadily approach their future professional career needs and requirements of their future employers. At an administrative level, discussion continues as to the requirements for General English versus ESP courses or a combination thereof. 
However, at the level of actual implementing and teaching ESP pre-intermediate level English courses, the teacher's observations and the students' feedback in the form of a survey are already providing food for development. Thus, when certain conditions and principles are adhered to, the implementation can be exceedingly beneficial, both for the teacher and the learners. The following bullets summarise the teacher's observations, as noted throughout the course over four semesters:

- The pedagogical aim of the course and individual activities must be defined and strictly maintained, always bearing in mind the pre-intermediate-level of the learners and their needs;

- Appropriate up-to-date ESP textbooks and other materials must be identified carefully to enable learners to adapt;

- The content of the texts should be selected judiciously to meet the students' practical interests and actual needs, whilst keeping the technical focus at a more general level, considering the pre-intermediate level

- The balance between interesting content and important language must be maintained in order not to overwhelm the students;

- A gradual introduction to subject-related, selected language and grammar structures works most efficiently;

- A focus on developing more generic skills that are not as dependent on language is beneficial;

- Providing authentic technical contexts and other life contexts (as permitted within the framework of the specific ESP course) which learners may encounter is imperative;

- The selective and sympathetic feedback on any fulfilled tasks should be immediate;

- The teacher must be well-prepared and confident to manage the authentic technical settings and firmly convinced of the importance and efficiency of the tools employed, as Lustigova highlights (2012: 56), confirming that "once the teacher is convinced, the students themselves will also begin to see the corresponding value.";

- Students should be encouraged to become active participants of the teaching-learning process, thus, their motivation should be maintained at a high level by varied interesting topics, as well as flexible teaching methods.

As confirmed above, this focus on the learners' needs indeed becomes paramount and is substantiated by Gatehouse (2001: 2). As shown in the student survey, students' views and needs must be taken into account and should aid in determining the course objectives and selection of teaching methods and tools. Ignoring students' wants might lead to "resentment and lack of motivation" as stated by Snyder in Kashani, Soheili and Hatmi (2006: 86). Based on the students' needs, Katz, in Kashani, Soheili and Hatmi (2006: 85), emphasizes "the appropriateness of the tasks and activities to the learning style of the learners and their knowledge" which must be maintained at all times and under any circumstances. As noted in the tasks explained above, the learning tasks should be straightforward, clear and realistic and should strictly coincide with the learners' pre-intermediate level of proficiency. The teacher should assist the learners' at any time, as it would be unwise to expect pre-intermediate level students to work on projects and carry out other student-generated activities without guidance; this principle is emphasized in Taylor (2001: 41). Such challenges establish an extensive space for expansive research towards solutions, including eventual textbook writing and more extensive teacher training in ESP 
possibilities on a larger scale and in terms of the classroom, for the collection of other physical technical materials which may be difficult to locate.

Another challenge to be considered is the balance between the language and content taught in A2 ESP classes. Whilst students value content which is usually linked with their study field and their future professional focus, they also need certain language structures and grammar to express themselves, offer opinions, and fulfil given tasks. Moreover, they need to acquire some language functions to communicate with fellow students or future colleagues on general topics. As noted earlier, the implementation sequence of these functions, and especially of the grammatical structures, into the lessons may differ from the usual order of acquiring grammar in General English courses. However, according to Lowe (2009: 1), the content should always lead language. In all cases, the level of exposure to either content or grammar should be further researched for different levels and various ESP courses. Looking ahead to more flexible teaching situations, Tsao, Wei, Fang (2008: 259) advocate future research on different educational settings. Specifically for the pre-intermediate ESP class, this may include class field trips to technical sites, where students are able to meet technicians who speak about their topic in English. It could also comprise visits of the university students to high-school level English classrooms in order to present some of their invented gadgets, etc. Stimulation towards future ESP study, and in this case specifically TE, could thus be prompted and the students themselves likewise given opportunities to contribute to society. Given the pre-intermediate-level of English proficiency, the discussion of using L1 in the language classroom is pertinent. In the classes observed, the majority of the lessons were led in the second language (L2) whilst keeping the L2 simple and comprehensible for all. Any unclear vocabulary or instructions were explained several times in L2 and only later on translated into L1, if required by the learners. However, the research and tasks for this paper did not focus on these issues, as this would be a side-line destined for forthcoming research.

Furthermore, in terms of the students' motivation and participation, it was made clear that an authentic technical and life context should be established and accommodated, in order to successfully communicate and to augment students' positive attitudes and participation. This is a concept likewise claimed by Gatehouse (2011: 6). Any ESP texts, when adjusted and well prepared by the teacher to better correspond to the students' current knowledge of the subject matter and their language proficiency, also help the students in overcoming confusion which might often result in "overexposure to new materials" and decrease the motivation which is "central to all learning", according to Johns (1985: 1). TE, in particular, enables an entirely authentic technical context to be constituted early on within the lessons, thus simulating the actual situations in companies which students will join in the very near future. This paper serves as a recommendation for future research on ESP materials development and issues of their authenticity and modification; such research would serve as an important followup to the issues already established for example, by Johns (1985: 130-107) or Fellner (2011: 15), who had focused on teaching ESP to pre-intermediate-level students through presentations.

Despite all of the above-mentioned, worthwhile results in terms of A2 TE course, a set of potential barriers is also engaged by the teacher:

- classroom time constraints due to the low number of lessons throughout the academic year

- classroom time constraints due to class size 
- the teacher's sensitive involvement in the teaching-learning process

- the teacher's potential low competence level in ESP/TE

- the students' limited knowledge

- the students' various language capabilities

- institutional requirements of GE versus ESP

- institutional support of ESP at more general level

To overcome the time constraints within the lessons, the teacher must be well-prepared and devote enough time to lesson preparation to be well-versed in employing the above-described tasks in A2 TE lessons. The fact that authentic materials and pertinent documents were to be used (real video sessions, presentations of company comparisons, descriptions of objects and machine models or safety test role-playing) necessitated a certain amount of extra preparation time outside of the classroom both for the teacher and the students. However, this extra time spent on preparation is advisable, in terms of the teacher, and allows for a smooth atmosphere to be set forth in the classroom. The teacher's competence can be further enhanced by attending and/or providing sufficient teacher training opportunities for ESP projects. Teacher training can also be complemented with intensive self-study, as well as research and discussion of other teachers' experiences.

In terms of further ameliorating teacher-student communication, this paper has confirmed the findings of Martinovic and Poljakovic (2010: 156) on smaller classes reaching better results. Nowadays, this issue represents a large-scale problem in language teaching and ESP in particular. Governmental policies regarding the educational sector in certain countries has led to an enormous increase of students attending universities, thus the overall quality of the educational process may decrease. The class sizes for full-time learners of a language vary from 30 to 35. For distance learning, the bar is raised; courses where there are more than 100 students per 1 teacher are not exceptional. Solutions to these large class sizes will take time and may best be stimulated towards change by surveys which students submit to the university.

Another barrier to efficient integration of pre-intermediate-level ESP course into university language teaching may be the limited knowledge of the students and sometimes heterogeneous groups of learners, comprising multiple levels of knowledge. Although the level of language within the articles, videos, technical drawings and documentation can be modified by the teacher, this does not necessarily compensate for large gaps on the part of certain students. These gaps can be tackled with suggested home preparation as a definite prerequisite to the students' success. Throughout the four semesters, considerable group heterogeneity was not experienced within the stated research; fortunately, the level of all participating students was rather equal.

Finally, despite the students very positive attitude to ESP, the inadequate promotion and support of ESP at the institutional level is considered one of the most significant limitations to further implementation of these courses. However with time and the progression of the market on the whole, the university's approaches may transform as well. Considering the current increase in student numbers, there is added significant potential for exploiting the students' motivation and their awareness of more specialised language for their future. As further research is published, the hope runs high for a direct result in terms of added courses. 


\section{Conclusion}

The classroom-based research for this paper aimed to prove the feasibility and efficiency of implementing ESP and TE, in particular, to the pre-intermediate classrooms. The research was executed in the classes of Technical English students at the Czech University of Life Sciences Prague during the two following academic years. Students were from different technical backgrounds having different technical subjects as their major. The design and selection of materials and teaching tools had to address this reality. The tool of task-based learning was utilised in a form of authentic problem-solving tasks and real video sessions tasks to prove the fact that that wisely used teaching methods make teaching ESP even to pre-intermediate students feasible and efficient. The method of observation in combination with the students' survey of their attitudes, satisfaction and needs was chosen. By implementing the proper approaches and tools while keeping all principles of teaching pre-intermediate students a measurably positive impact on the improvement of students' language skills and various soft skills was achieved. Described activities provoked attention, motivation and the ultimate active participation of the Technical English students and made the initial steps in their preparation for actual workplaces and future studies. The paper also indicates that insisting on an authentic technical context and context students' lives brought substantially increased positive effects, far beyond the simple improvement of the students' language skills.

Since multilanguage and multicultural environment became a general standard of most companies, the need to acquire necessary language knowledge is paramount. The traditional university environment should follow the learners' needs for eventual professional positions, as the students need to "function in the workplaces of today's society" (Bingimlas, 2009: 236). The scope of forthcoming ESP courses potentially encompasses almost every profession where the English language could conceivably be beneficial. If 'the sky is the limit', then it remains to educational institutions, teachers and eventual students to recognize the need and respond accordingly. Meaningful response, as opposed to reaction, takes time. The same follows for ESP pre-intermediate course development. Although it might be simple to say that ESP, as a field, should keep pace with the world which it serves, this operation is often decelerated by numerous barriers, as detailed previously. In addition, the inherent variety found in the world can be the same as found in the analogous ESP courses, provided that the development is well thought-out initially, flexible over the learning process and visionary towards future requirements, either from the market externally or from the classroom internally. Within such a context, Maslow's celebrated statement has special reverberation, "...it is tempting, if the only tool you have is a hammer, to treat everything as if it were a nail," (1966: 15), since indeed it would be appealing to suddenly have a hammer on offer for every nail which seems apparent. Correspondingly, however, if the larger tool available is ESP as a whole, with its intrinsic characteristic of adaptation, its actual application to courses and those taking the courses must be tailored with care. Given the potential ideal situation where educational establishments support ESP course development and students call for ESP courses, either directly via exposure to other similar courses or indirectly via professional pressures, this type of tailoring ultimately rests in the hands of the teacher. Orr targets teachers as those in need of particular reinforcement, especially in cases where they may be asked by administrations to develop ESP courses for subjects in which they are not specialised, “... 
language specialists who select ESE [English language education for science and engineering students] as their profession simply need to share the same curiosity for knowing about the world and the same drive for finding effective solutions to problems they encounter" (Orr, 2010: 228). Thus if curiosity can be tapped or triggered on the part of the teacher, any students, including those with low-level of English proficiency, will likewise respond favourably, aiding in classroom teacher-student integration in larger measure than may ever have been expected.

\section{References}

Bingimlas, K. A. (2009) 'Barriers to the Successful Integration of ICT in Teaching and Learning Environments: A Review of the Literature', Eurasia Journal of Mathematics, Science $\mathcal{E}$ Technology Education, Vol. 5, No. 3, pp. 235-245, ISSN 1305-8223, Available: http://www.ejmste.com/ [September 2013].

Dudley-Evans, T. (1998) Developments in ESP: A multi-disciplinary approach. Cambridge: Cambridge University Press.

Fellner, T. (2011) 'Developing an ESP Presentation Course for Graduate Students of Science and Engineering', Saga University Centre for Research and Development of Higher Education - University of Education annual report, Vol. 7, pp. 1-16, Available: http://www. crdhe.saga-u.ac.jp/SJHE_No.07_Fellner.pdf [September 2013].

Gatehouse, K. (2001) ‘Key Issues in English for Specific Purposes (ESP) Curriculum Development', The Internet TESL Journal, Vol. VII, No. 10, Available: http://iteslj.org/Articles/Gatehouse-ESP. html [September 2013].

Harmer, J. (2007) The Practice of English Language Teaching, Harlow: Pearson Education.

Hollet, V. (2005) Tech Talk Pre-Intermediate Teacher's Book. Oxford: Oxford University Press.
Hutchinson, T. and Waters, A. (1987) English for Specific Purposes - A Learning-Centred Approach, Cambridge: Cambridge University Press.

Johns, A. M. (1985) 'The New Authenticity and the Preparation of Commercial Reading Texts for Lower-Level ESP students', CATESOL Occasional Papers, No. 11, pp. 103-07, Available: http://eric.ed.gov/?id=ED263770 [September 2013].

Kashani, A. S., Soheili, S., Hatmi, Z. N. (2006) ‘Teaching English to Students of Medicine: A Student-Centred Approach', Asian ESP Journal, Vol. 2, No. 2, pp. 85-98, ISSN 1833-3001, Available: http://asian-esp-journal.com/November_2006_EESPBook.pdf [September 2013].

Kavaliauskiene, G. (2005) 'Task-Based learning and Learning Outcomes in the ESP Classroom,' CEEOL Studies About Languages, Vol. 2005, No. 7, pp. 66-70, ISSN 164-2824, Available: h t t p:// w w w. cee ol.com/a s px/is suedetails. aspx?issueID=65954f87-40c6-4d45-b2f9-5510a290a2a8\&tabID=0 [September 2013].

Lonergan, J. (1984) Video in Language Teaching, Cambridge: Cambridge University Press.

Lowe, I. (2009) 'Principles of ESP course design', Available: http://www.scientificlanguage.com/esp/coursedesign.pdf [September 2013].

Lustigova, L. (2012) 'ICT Challenges in the $21^{\text {st }}$ Century Business English University Classroom', Journal on Efficiency and Responsibility in Education and Science, Vol. 5, No. 2, pp. 4662, ISSN 1803-1617, Available: http://www. eriesjournal.com/_ papers/article_171.pdf [September 2013].

Martinovic, A., Poljakovic, I. (2010) 'Attitudes toward ESP among University Students', Fluminensia, Vol. 22, No. 2, pp. 145-161, Available: hrcak.srce.hr/file/97888 [September 2013]. 
Maslow, Abraham H. (1966) The Science of Psychology: A Reconnaissance. New York: Harper and Row.

Orr, T. (1997) 'Studying the Professions We Serve', The Language Teacher Online, Vol. 21, No. 08, pp. 11-12, Available: http://jaltpublications.org/tlt/issues/1997-08_21.8 [September 2013].

Orr, T. (2010) English Language Education for Science and Engineering Students In M. F. Ruiz-Garrido, J. C. Palmer-Silveira and I. Fortanet-Gómez (Editors), English for Professional and Academic Purposes (pp. 213 - 230), Amsterdam - New York: Rodopi B.V.

Ruiz-Garrido, M. F., Palmer-Silveira J. C. and Fortanet-Gómez, I. (2010) Current Trends in English for Professional and Academic Purposes In M. F. Ruiz-Garrido, J. C. Palmer-Silveira and I. Fortanet-Gómez (Editors), English for Professional and Academic Purposes (pp. 8 - 15), Amsterdam - New York: Rodopi B.V.

Strevens, P. (1988) ESP after Twenty Years: A Re-appraisal. In M. Tickoo (Ed.), ESP: State of the Art (pp. 1-13). Singapore: SEAMEO Regional Centre.

Taylor, J. (2001) The Minimax Teacher, Peaslake: Delta Publishing. Thornbury, S. (2006) An A - Z of EFL, Oxford: Macmillan Publishers Limited.

Tsao, C., Wie, A., Fang, A. (2008) 'ESP for College Students in Taiwan: Survey of Student and Faculty Perception', Proceedings of the 2008 Symposium on ESP, pp. 245 - 262, Available: http:// ir.fy.edu.tw/ir/bitstream/987654321/2992/1/13\%20ESP\%20 for $\% 20$ college $\% 20 S$ s 20 in\%20Taiwan.pdf [September 2013]. 